\title{
Colonialismo digital, atención y lectura en tiempos de cambio
}

\author{
Digital Colonialism, attention \\ and reading in times of change
}

Pedro Medina Reinón

Director del Área Cultural del Istituto Europeo di Design (IED Madrid)

Javier Maseda Ramos

Director de Creatividad del Istituto Europeo di Design (IED Madrid)

Fecha de recepción: 22 de octubre de 2013

Fecha de revisión: 19 de enero de 2014

Para citar este artículo: Medina Reinón, P. y Maseda Ramos, J. (2014): Colonialismo digital, atención y lectura en tiempos de cambio, Icono 14, volumen (12), pp. 244-266. doi: 10.7195/ri14.v12i1.660 


\section{Resumen}

A partir del libro "Contro il colonialismo digitale" de Roberto Casati, se analizan las nuevas formas de lectura de textos digitales para establecer sus especificidades, principalmente en lo que concierne a posibles cambios cognitivos, con el objetivo de estudiar cuál puede ser el medio idóneo destinado a la enseñanza. Este análisis tendrá una primera aproximación ontológica al texto digital para reflexionar posteriormente sobre las prácticas que se están implantando en nuestra sociedad.

\section{Palabras clave}

Texto digital - Libro - Lectura - Percepción - Atención - Enseñanza

\section{Abstract}

On the basis of the book "Contro il colonialismo digitale" by Roberto Casati, the new ways of reading digital texts are analysed to establish their specific characteristics, especially with regard to possible cognitive changes, with the aim of assessing which is the optimum system to apply to the realm of education. This analysis will entail an initial ontological approximation to digital texts in order to subsequently reflect on the practices that are being introduced to society.

\section{Key Words}

Digital text - Book - Reading - Perception - Attention - Teaching 


\section{Introducción}

Roberto Casati (2013) se ha convertido recientemente en la figura que ha personificado la reacción contra los medios digitales en lo que al formato libro se refiere, tanto de los nostálgicos del libro en papel, como si el digital lo condenara a muerte, como de aquellos que sufren la entrada de los medios digitales en las aulas.

Da voz pues a las dudas sobre una nueva constelación, la digital, en un contexto donde las convicciones formales y comerciales han saltado por los aires. Muchas de las cuestiones surgidas ya fueron planteadas por Luis González (2009) en Nuevas formas de lectura en la era digital, donde identifica varias creencias populares: la insistencia en el número decreciente de lectores, la desaparición del libro tradicional -en la Feria de Frankfurt de 2009 ya se auguraba su muerte para 2018- o el desprestigio de las obras generadas en ámbitos digitales frente a las obras en papel, en vez de ver las posibilidades positivas que aportan las nuevas tecnologías.

Alguien como Janet Murray, poco después de incorporarse al Laboratorio para la Tecnología Avanzada en Humanidades del MIT, bajo la dirección de Nicholas Negroponte (1995) -el autor de Being Digital-, resumía la situación: “El nacimiento de un nuevo medio de comunicación es al mismo tiempo fuente de entusiasmo y temor. Cualquier tecnología industrial que extienda espectacularmente nuestras capacidades nos pone también nerviosos al cuestionar nuestro concepto de humanidad"1; $^{11}$ una declaración en la línea de Marshall McLuhan (1962), quien sostenía que toda tecnología tiende a crear un nuevo contorno para la humanidad.

Este miedo o esta esperanza en el paso de la Galaxia Gutenberg a la Galaxia Internet no se puede concebir como un panorama de comunidades enfrentadas, definidas por la primavera de los "nativos digitales" -a pesar de que Casati niegue su existencia- contra el invierno de los "inmigrantes digitales" -en términos de Marc Prensky (2001)-, sino que debe prevalecer una discusión sobre la propia lectura como aquello que propicia el conocimiento en la sociedad de la información. 
Más allá de fascinación alguna por el medio, conservemos nuestra atención sobre los contenidos y los procesos, pero sin olvidar que el medio condiciona necesariamente lo percibido.

No obstante, indudablemente están cambiando los hábitos de lectura y la industria en torno a los mismos. El paralelismo más obvio con nuestra época es el establecido por la imprenta y el impacto que tuvo su aparición en la construcción del pensamiento de su época. En cualquier caso, convendría separar los contenidos del soporte que se utiliza para acceder a los mismos. Al respecto, Luis González recuerda la Ley de la lectura, del libro y de las bibliotecas de 2007, que consagra legalmente un concepto de libro: “a) Libro: obra científica, artística, literaria 0 de cualquier otra índole que constituye una publicación unitaria en uno o varios volúmenes y que puede aparecer impresa o en cualquier otro soporte susceptible de lectura"'2.

Así, al margen del medio, debemos situarnos en una sociedad de la información cuya dimensión globalizada y tecnificada establece otra relación con el conocimiento. Y esta realidad sí que hace más pertinentes o actuales unas plataformas que otras. Luis González propone hablar de "procesos" de acceso al conocimiento, yendo más allá del soporte para hablar de lectura, es decir, del acto de leer desarrollado por un sujeto lector, de forma coherente con unos comportamientos culturales que no pueden quedarse en una dimensión objetual, sobresaliendo la importancia del sujeto que lee y la utilización crítica de la información y el conocimiento.

A ello se dedicará este artículo, para analizar este paso, sobre todo como método de aprendizaje y su aplicación a la enseñanza.

\section{Metodología}

Todo sistema establece unas condiciones que afectan a la relación entre sus partes. En el caso de la lectura en la época del texto digital podríamos establecer dos dimensiones principales: una ontológica (definición de las características propias de los textos digitales) y otra comercial o industrial (relativa al mercado) ${ }^{3}$, que en su conjunto deberían desvelarnos la lógica de la producción creativa en torno al texto digital. 
En este artículo atenderemos principalmente la primera dimensión de análisis con el objetivo de descubrir y justificar en qué términos se está estableciendo esta discusión en torno al paso del texto en papel al digital, identificando los conceptos claves y su significado, para descubrir las especificidades propias del digital en función de los cambios cognitivos que supone y en vista a la enseñanza y asimilación de los contenidos.

En este sentido, se analizarán en un primer momento las características formales para pasar a continuación a las prácticas, es decir, a los usos e implantaciones del texto digital. Y en este segundo análisis, se confrontarán teorías sobre la percepción y la lectura para sacar conclusiones, orientadas principalmente a la enseñanza.

\section{Desarrollo}

\subsection{Ontología del texto online}

En un primer momento, conviene establecer una serie de aclaraciones que nos permitan entender cuáles son las características propias de las publicaciones digitales, ya que el propio Casati no cree que haya una serie de avances significativos.

Al margen de aclaraciones sobre soportes y medios ${ }^{4}$, centrando el profesor italiano la atención sobre libros electrónicos en tabletas, se ha de reivindicar que hasta ahora el libro en papel, vencedor histórico frente a otros soportes como la arcilla o el pergamino, ha tenido un carácter fundamental en nuestra cultura, pero cabe señalar que ha sido entendido en su dimensión objetual, lo que construye una imagen en la que se identifican contenedor y contendido. Sin embargo, con la llegada de la era digital queda de manifiesto que el libro es el texto -sobre todo cuando hablamos del formato ePub-, dando más importancia al contenido que al formato, lo que rompe el tradicional vínculo entre los textos (las obras) y los objetos (los libros). No importa el soporte sobre el que se lea, el contenido reina sobre el continente. 
Aun así, en la lectura digital y en la lectura en papel aparecen factores diferentes y se crean experiencias distintas, al igual que ocurre entre la lectura en la pantalla del ordenador y la comodidad que aportan las tabletas, siendo los elementos hápticos de la lectura muy relevantes, porque leemos con todo el cuerpo y no solo con los ojos 5 . De hecho, Casati hace hincapié en el tacto para saber el progreso en la lectura y la cercanía del final, para no distraer la vista, aunque el sistema de paginación o líneas de referencia no suponen en ningún caso una gran distracción.

Pero no solo se transforma la experiencia de los contenidos, también cambia la relación que se establece entre el lector y el escritor, o entre los lectores entre sí, al compartir su experiencia de lectura (algo que se puede aumentar hasta el infinito en el medio digital).

El libro hasta ahora era un objeto inmutable, en el libro digital ocurre todo lo contrario: es fluido, cambia constantemente según el soporte y según las preferencias del lector, ya no hay páginas sino un porcentaje leído, podemos subrayar, hacer anotaciones, compartirlas con otros lectores, compartir páginas, leer en conjunto; la lectura pasa de ser algo íntimo a algo social, como en los clubs de lectura, pero ahora con todas las potencialidades de lo online.

Por tanto, el mundo digital conlleva para el universo de la lectura:

1. Nuevas formas de escribir.

2. Nuevas formas de leer.

3. El contenido es fluido y dinámico (texto, imágenes, vídeos, audio...).

4. El formato o artefacto ya no es rígido.

5. Experiencia individual vs. experiencia compartida.

6. Realidad aumentada en el libro = lectura aumentada = conocimiento aumentado $=$ conocimiento compartido.

7. Notas a pie de página vs. hipervínculos. 
Asimismo, podríamos establecer distintos tipos de libros digitales:

1. Sin formato: compuesto únicamente de texto, aunque pueden contener imágenes; en su formato digital carece de páginas: ePub, Mobi (Kindle), html.

2. Formato definido inalterable: se maquetan como los libros impresos y su maqueta permanece inalterable: pdf, ePub3, html5 y css3.

3. Formato definido alterable: se maquetan siguiendo el modo de las páginas web y su maqueta puede alterarse dependiendo del soporte, formato de pantalla, resolución, etc.: ePub3, html5 y css3.

4. Interactivos: se maquetan y programan como aplicaciones para un sistema operativo o mediante html5; incluyen elementos interactivos y animaciones, y su narración puede ser no lineal: iOS, Android, ePub3, html5 y css3.

De todos ellos, el ePub3 será el próximo estándar de facto de los libros electróni$\cos ^{6}$. Se supone que traerá interactividad, contenido multimedia, formato para los textos, estandarización de los contenidos, permitirá conversaciones sobre su libro dentro del libro, independientemente del servicio donde se haya comprado... Es la promesa del "network book" o "social book".

Son justo estas posibilidades, principalmente por la cercanía de "distracciones", lo que despierta el recelo de Casati. Bien por desconocimiento o por salto generacional, la extrañeza sigue siendo bastante generalizada, aunque todos los que nacimos leyendo y escribiendo de una manera, moriremos leyendo y escribiendo de otra, como afirma Antonio Fraguas (2012) en su Usted ya no lee ni escribe como antes. Esto supone que se revise la posición del escritor y el editor, la forma en la que el autor concibe su obra y la aparición de subgéneros más ágiles y dinámicos, quizás en parte propiciados por la velocidad de los tiempos que corren y de las nuevas plataformas donde esto es contado.

Ya estamos adelantando algunas de las consecuencias de este cambio de paradigma, pero antes conviene entender bien las características propias del texto digital y el sistema en el que se integra. Su inmediatez, ubicuidad y capacidad de generación hacen de él un medio ideal de comunicación en un mundo globalizado,

DOI: ri14.v12i1.660 | ISSN: 1697-8293 | Año 2014 Volumen 12 Nº 1 | ICONO14 
pero es sobre todo a raíz de las posibilidades transmedia y del devenir "social" de la web, instaurándose un nuevo modelo basado en las redes sociales, cuando se enfatizan los procesos colaborativos y abiertos en el mundo online, como iremos viendo más adelante.

En general, todas estas constelaciones deben entenderse dentro de un "sistema-red", es decir, en el interior de una estructura social en red donde la conectividad es la promotora principal de oportunidades comunicativas o relacionales ${ }^{7}$. Este sistema-red construye el gran laberinto contemporáneo dentro de un juego de relaciones entre un capitalismo social y las innegables capacidades de comunicación al alcance de todos. Es precisamente la "participación" (ya existente antes de la web 2.0) lo que ha dado lugar a un nuevo paradigma y al conjunto de prácticas sociales que le son propias, especialmente desde que podemos acceder a la información desde dispositivos portátiles.

Aparece ahora todo un universo "colaborativo", que responde a una lógica inclusiva basada en un hecho: una "determinada aplicación o red social será mejor cuantos más usuarios hagan uso de ella, es decir, que hay valor en el volumen, lo cuantitativo deviene cualitativo en esta época segunda de la web. Se entiende así que el empeño de las nuevas empresas de la web sea generar la necesidad de pertenencia y participación" (Martín Prada, 2012) y esta participación se traduce en generación de datos y, por tanto, en un valor, pues son rastreados por sistemas de seguimiento de los sistemas de gestión de esas plataformas.

\subsection{Rol activo del lector y lectura social}

La web 2.0 ha propiciado la construcción de un paradigma colaborativo en el que participa una multitud interconectada. El usuario se convierte ahora en protagonista y no en mero espectador, generando un espacio común. La "interactividad" es el término preciso para este ámbito ${ }^{8} \mathrm{y}$, en realidad, sería un estadio más de esa enfatización del rol activo del espectador que ya iniciaron las vanguardias históricas y que potenciaron los nuevos comportamientos artísticos a finales de los sesenta, aunque con una dimensión económica y social mayor, disolviéndose la clásica contraposición entre objeto y proceso, autor y espectador, productor y

ICONO14 | Año 2014 Volumen $12 N^{\circ} 1$ | ISSN: 1697-8293 | DOI: ri14.v12i1.660 
usuario en gran parte de las dinámicas activadas, que nos permite hablar de creación colectiva ${ }^{9}$.

Desde la perspectiva de varios movimientos artísticos, esta "cocreación" se entendió como potencial político y praxis social dentro de una recepción más activa de las obras por parte de los espectadores. Y si nos mantenemos en el ámbito de Internet, más que en otras concreciones de lectura digital, hoy el "tú eres la información" lleva al extremo lo vaticinado por Walter Benjamin (1936), cuando percibió que la Humanidad, "que antaño, en Homero, era objeto de espectáculo para los dioses olímpicos, se ha convertido ahora en un espectáculo de sí misma".

No obstante, conviene matizar el carácter activo del lector, ya que hay mucho más contenido filtrado por el usuario que contenido generado por el mismo. El lector o usuario ahora es un prescriptor de conocimiento, actuando como juez y parte de lo que encuentra. Dependiendo del criterio del mismo, ese artículo puede seguir promocionándose, a través de sus amigos, o finalizar su camino en él.

No obstante, también son muchos los que ya avisaban hace unos años del alienante fluir de lo mediático y de la efectiva manipulación del usuario tras su aparente interactividad y poder en la $\operatorname{Red}^{10}$.

En cualquier caso, si nos centramos en el acto de lectura, hay que reconocer que siempre fue interactivo, necesitaba del espectador en la concreción de todo texto, pero aunque el proceso de interacción sea común a todas las obras artísticas, con la llegada de las tecnologías digitales se intensifica la interactividad e incluso la "huella" que generan los lectores; como ocurre con opciones en plataformas como Kindle, donde puedes apreciar, por ejemplo, los párrafos subrayados por anteriores lectores.

Ante este panorama, ¿cuál será la lectura del futuro? En los últimos años son innumerables los foros (online y offline) que debaten sobre esta cuestión. Por citar uno, el blog Findings inició a finales de febrero de 2012 una serie sobre el futuro de la lectura, donde distintos actores del sector comparten conclusiones. Una de las más llamativas fue del gurú de Internet Clay Shirky, que imagina una lectura 
más social: “La lectura social no crea una nueva categoría. La gente extracta y anota y comparte y debate y cita y mezcla. Todo esto pasa a todas horas. La lectura social introduce la idea del texto como un objeto usable. La idea de que lo leeré y luego haré algo con ello: esas acciones siempre estuvieron conectadas, pero fingíamos que no lo estaban porque el libro no tenía esas características. La lectura social está allí donde un grupo de gente habla sobre un determinado texto" (Collera 2012).

\subsection{Transmedia y contenido aumentado}

Este carácter colectivo ha de entenderse unido a lo que se entiende por "narrativa transmedia", que consiste en contar una historia en diferentes soportes y medios, lo que requiere el uso de varios lenguajes, además de un proceso de producción que involucra a otros agentes, además del autor, como pueden ser producción, edición, comercialización, marketing, etc.

La transmedia se viene aplicando desde hace tiempo en medios como cine, televisión o videojuegos, pero si nos centramos en el libro transmedia, este se caracteriza por presentar una historia contada desde diferentes plataformas y en la que el lector ya no es un sujeto pasivo, sino que puede alterar el curso de la narración o de la historia, transformándola en múltiples obras.

Esta puede ser una opción para que a las editoriales no les pase lo mismo que a las discográficas, ya que ahora mismo con las herramientas que un autor tiene a su disposición podría perfectamente prescindir de ellas, pero cuando llegamos al libro transmedia, vuelven a cobrar protagonismo, ya que son las que tienen el dinero y los recursos necesarios para poder producir una historia transmedia.

Sin duda, esta es una gran oportunidad para crear nuevos relatos, un campo sin explorar que puede dar lugar a grandes obras, seguramente protagonizadas por los nuevos escritores capaces de sacar partido a todos los medios disponibles a su alcance.

Por otro lado, dentro de esta ontología del texto digital hay que advertir que leer las obras en línea implica "ejecutarlas", es decir, se producen mientras se experimen-

ICONO14 | Año 2014 Volumen $12 N^{\circ} 1$ | ISSN: 1697-8293 | DOI: ri14.v12i1.660 
tan. Lo digital interactivo está sometido a un estado permanente de actualización en función de la interacción con el usuario, por lo que tendríamos que hablar de contenidos que están en gerundio, es decir, están "siendo-ahí" -en referencia al "ser-ahí" (Dasein) heideggeriano-, lo que dificulta la diferenciación del ver y el producir, del producir y el reproducir ${ }^{11}$. Podríamos incluso decir que la obra no es, sino que se transmite.

Esto diferencia claramente la lectura digital frente a la de soporte físico, planteando la posibilidad de que el contenido inmediato se relacione con más información, dentro de una poética de la yuxtaposición. Esto implica una forma distinta de estructurar el conocimiento y de entender el acto de lectura.

Frente a la cinematografía, que plantearía un montaje en el tiempo, las narrativas desde Internet al cd-rom, pasando por los libros digitales, plantean un discurso espacial en el que los contenidos se superponen como estratos de información interrelacionados. Es lo que llamamos "sistema hipertextual" (sistema no lineal de almacenamiento), que entroncaría con movimientos de ruptura de la linealidad narrativa tan frecuentes en la literatura del siglo XX desde el Finnegans Wake (1939) de Joyce hasta la Rayuela (1963) de Cortázar, pasando por tantos otros como William Burroughs, y de la que incluso existen antecedentes en el siglo XIII como la máquina de pensar de Ramon Llull, compuesta por discos concéntricos interconectados, o el Filmváz: A nágyváros dinamikaja de Moholy-Nagy en 1925, hasta llegar al sistema de almacenamiento de datos Memex, ideado por Vannevar Bush en 1945.

El hipertexto, según la definición de su inventor, Ted Nelson (1992), es “the most general form of writing". En general, podemos entender el hipertexto como un particular tipo de documento digital que se sirve de la tecnología más común en Internet, la web, y que implica un modo no lineal de estructurar la información, donde el link es la unidad fundamental que une el texto con el motor conceptual del hipertexto. Por tanto, las rupturas son obvias respecto a los principios básicos de la escritura impresa: no solo prescinde de la citada linealidad del significante (Saussure), sino también de todo contexto ${ }^{12}$. 
La convergencia de la hipertextualidad y de las posibilidades multimedia crean un nuevo tipo de lector, que, además, se adapta a los nuevos modos de socialización de los productos digitales respecto a diversos lectores. Lo que es importante reconocer es que se pasa de una lectura lineal a la navegación, mientras que en cierto sentido el lector se acerca a la posición del autor y cambia la noción de obra, que deviene un objeto colectivo y siempre in progress.

\subsection{Conservación del conocimiento y externalización de la memoria}

Este campo inmenso de posibilidades y caminos también plantea muchas dudas y críticas, ya que esta redefinición del concepto de lectura puede generar dispersión en el lector $\mathrm{y}$, sobre todo, cierto peligro que reside en la tendencia a la externalización de la memoria, sobre todo ante la aparición de sistemas de registro visual portátiles, que han permitido que la percepción sea progresivamente computerizada.

Ahí es donde residen las mayores críticas de Casati (2013), referidas a esos "informávoros" que somos los seres humanos, consciente de que "la cultura es un fenómeno muy complejo que no está legado solamente a los medios, sino a las prácticas sociales"13. Pero esperemos aún un poco a escuchar las mayores reivindicaciones de Casati, terminado de identificar las características propias del nuevo medio.

Esta idea centrada en que la percepción sea computerizada tiene como consecuencia que nuestra experiencia sea simultáneamente un registro técnico (en una memoria externa). Esta es una expresión de turista contemporáneo, que no vive su viaje sino que lo documenta, sustituyendo la visión por la "visualización"14; incluso se está produciendo un fenómeno curioso: se fotografía con el iPad, a pesar de su aparatosidad, para contemplar ya lo que se tiene delante tal y como se visualizará después. Se asume así la propia definición del concepto "visualizar" en la RAE: "hacer visible una imagen en un monitor".

ICONO14 | Año 2014 Volumen $12 N^{\circ} 1$ | ISSN: 1697-8293 | DOI: ri14.v12i1.660 
Precisamente McLuhan (1964) ya avisó en los sesenta: el hombre ha empezado a llevar "el cerebro fuera de su cráneo y sus nervios fuera de su piel"15, algo que sigue un frenético crescendo gracias a los dispositivos de almacenamiento digital y, aún más, a los aparatos móviles que llevamos con nosotros. Ahora la información es cada vez más fácilmente transmitible, editable, reutilizable... y, sobre todo, fácil de compartir, lo que parece implicar un vaciamiento de nuestra memoria biológica; si no, parémonos a comparar los números de teléfono que sabíamos de memoria y los que retenemos hoy día.

¿Pero es esto un fenómeno exclusivamente derivado de la digitalización del mundo? Basta ir a los orígenes de la escritura, tal y como nos los cuenta Platón, para percibir un dilema más antiguo. En textos como la Carta VII o el Fedro, Platón se muestra crítico con la escritura y toma partido por la oralidad para hacer filosofía y extraer el saber de sí mismo. La aparición de la escritura aparece vinculada a la mitología egipcia, inventada por el dios Theuth, y es presentada como phármakon, es decir, un remedio para la memoria y la sabiduría que combatiría el olvido, si bien Derrida (1969) destacó la ambigüedad del término, que puede ser cura pero también droga, por lo que Theuth habría hecho pasar un veneno por un remedio. Con el pretexto de suplir a la memoria, la escritura nos hace más olvidadizos, no acrecentando el saber que poseemos sino que lo reduce.

A pesar de la distancia y dejando al lado la teoría platónica de la memoria, Platón estaría achacándole a la escritura algo parecido a lo que se está imputando hoy al texto online, con la salvedad de que la crítica al texto escrito en Platón aparece en muchos casos vinculada a su condición de "discurso fijo" sin posibilidad de interpelación y sin las virtudes de la conversación, fenómenos que precisamente sí se pueden dar en las plataformas online y con un número de interlocutores enorme dentro de la red global. ¿Esto nos puede conducir a procesos ad infinitum?

\subsection{Mal de archivo}

Es precisamente Derrida (1994) quien expone otro problema de la sociedad contemporánea: el "mal de archivo", que plantea más consecuencias que el término de moda "infoxicación", no obstante más vinculado al mundo digital, don-

DOI: ri14.v12i1.660 | ISSN: 1697-8293 | Año 2014 Volumen 12 Nº 1 | ICONO14 
de Internet presenta procesos desmesurados para la experiencia y la memoria humanas.

El actual impulso hacia la memoria colectiva corre el riesgo de caer en el abismo del delirio cuantitativo. Hoy hablamos de sobresaturación de información, pero al mismo tiempo se detecta la pulsión a archivarlo y controlarlo todo con la pretensión de salvaguardar la memoria del olvido. Uno de los proyectos más interesantes que han observado este fenómeno ha sido el que activó Jorge Blasco (2000-), Culturas de archivo, como un buen exponente de una larga tradición ${ }^{16}$. Este proyecto estudia las estrategias de construcción-destrucción del archivo, sus prácticas de producción de sentido, que implican la creación de realidad desde su clasificación, gestión y representación, haciendo especial hincapié en la condición represora del archivo, aunque sin olvidar su dimensión como testigo.

Esto enlazaría con aquella historia de una ambición que Blumenberg recogió en los últimos capítulos de La legibilidad del mundo, que ya desde Novalis, que se propuso escribir un "libro absoluto" (visto como una "enciclopedia" o una "biblia"), se puede rastrear hasta Humboldt, quien con Kosmos intentó la "descripción del universo físico". Esta aspiración es recogida por Italo Calvino (1988) dentro de su capítulo sobre la "multiplicidad", que comienza con Carlo Emilio Gadda -porque sabía que "conocer es insertar algo en lo real y, por tanto, deformar lo real"- hasta llegar a las grandes novelas del siglo XX, concebidas como enciclopedias "abiertas" que ya nos hacen entender -mucho antes de estos litigios con lo digital- que "hoy ha dejado de ser concebible una totalidad que no sea potencial, conjetural, múltiple".

Hoy día nos encontramos con Internet como la gran enciclopedia abierta, en continuo proceso, que pretende captar el mundo precisamente en su mutabilidad. Y es ahora cuando los dos lugares de archivo por excelencia, el museo y la biblioteca, quedan empequeñecidos por la gran biblioteca digital, soñada como "electrobiblioteca" por El Lissitzky (1923), o ideas similares que encontramos en Jorge Luis Borges o Alain Resnais, entre otros. Este sueño, que se remonta a la Biblioteca de Alejandría, parece posible gracias a la digitalización y puesta en común de las colecciones custodiadas por las bibliotecas y el ofrecimiento de fondos privados. 
Entre los ejemplos más llamativos, la biblioteca digital mundial de Google, sometida a cuestiones preferentemente comerciales, y proyectos de preservación de la cultura como la biblioteca digital europea Europeana, que cuenta, entre otros, con los fondos integrados de la Biblioteca Digital Hispánica de la Biblioteca Nacional, o la Biblioteca Digital Mundial, auspiciada por la Library of Congress ${ }^{17}$.

El panorama de acceso a la cultura es impresionante, sin embargo, no son pocas las paradojas de esta pulsión enciclopedista, sumida en la trepidante acumulación de conocimiento de nuestros días y la imposibilidad de abarcarla. En cualquier caso, ya nadie osa afirmar, como Pico della Mirandola en el siglo XV, que lo sabe todo, más bien hay que saber cómo administrar este nuevo phármakon que pone a nuestro alcance todo aquello que queramos preguntar.

\subsection{Atención, enseñanza y formas de lectura}

Si pensamos en la conveniencia del libro digital, vuelven las dudas y las críticas sobre el "ruido" existente en torno al texto, que dificulta la concentración del lector $^{18}$. Una vez más se plantea el libro tradicional como el ideal para sumergirse en la lectura y los sopotes digitales como un menú de distracciones que fragmentan la experiencia.

Es este el punto central del libro de Casati (2013), con afirmaciones como "el zapping no forma parte de las opciones de lectura", reivindicando la linealidad como forma cognitivamente mejor -como si ilustraciones y notas no fueran una interrupción como las que plantea cuando critica recursos multimedia, o como si la estructura "completamente lineal" fuera la única forma; ¿qué dirían Cortázar, Borges, Italo Calvino, Ramon Llull, los poetas visuales, los creadores de libro-aventuras...?

Su posición se resume de la siguiente forma: "el libro en papel presenta una serie de ventajas cognitivas propias allí donde se quieren imputar límites tecnológicos que el ebook superaría: la linealidad que permite simplificar la comprensión, ofrecer argumentos e el espacio de una página estable y no desplazable que permite tener a la vista muchos pensamientos a la vez, el aislamiento relativo respecto 
a otros artefactos cognitivos que podrían entrar en competencia con la lectura, el mismo peso físico del libro como fuente de informaciones...".

Y acude a estudios cognitivos para apoyar sus tesis, aunque en concreto en este caso sea a uno ya viejo de Craik y Tulvig (1975), para realizar afirmaciones tan rotundas como "no se han abierto nuevos horizontes para la lectura de textos en un nuevo formato; esta lectura, en cambio, ha sido robada" (Casati 2013). Lo que sorprende si tenemos en cuenta los datos dados con anterioridad sobre narración transmedia y lectura social, que parece rechazar como algo implícito de la lectura, pero cuyo discurso dialógico le es connatural, como bien sabía Platón.

Aun así, Casati (2013) no siempre resulta reaccionario, fundamenta varias posibilidades a las que adaptarse -“han sido creados nuevos ecosistemas, ricos e interesantes que redefinen completamente las prácticas"- aunque pervive un carácter de resistencia respecto a los procesos cognitivos activados por un soporte y otro, principalmente en torno a la atención, mientras intenta defender que las nuevas tecnologías no representan una innovación cognitiva epocal, rechazando "pensamientos arborescentes" y nuevas formas de inteligencia, que establecen caminos paralelos y discontinuos.

Pero al margen de estas cuestiones epocales, centrémonos por un momento en la ventaja cognitiva del libro en papel para favorecer la atención y la comprensión del texto. Hay varios estudios al respecto, uno de los más citados -aunque curiosamente no por Casati- es el que se llevó a cabo en 2011 en el TechnionIsrael Institute: se les dio a leer un texto expositivo en el ordenador a un grupo de estudiantes y a otro grupo el mismo texto en papel. Después de 7 minutos los estudiantes respondieron a preguntas de compresión del texto: los resultados de los dos grupos fueron iguales. Los investigadores repitieron el experimento dando más tiempo para leer, tanto como los estudiantes quisieran. Los que estudiaron en papel tuvieron resultados un $10 \%$ mejores resultados que el otro grupo.

Sin embargo, estos estudios parten de una falta de discriminación de base equivocada: por texto digital entienden el ordenador, y sobre él se hace la prueba, como si fuera igual la lectura en ordenador que en tableta o móvil, cuando todos 
los estudios a favor del libro en papel que hablan de ergonomía se podrían aplicar igualmente a la tableta pero no al ordenador o el móvil. Y lo más importante, no se hacen estas pruebas tiempo después, una vez que los mismos sujetos de la experimentación han adquirido una mayor familiaridad con los medios digitales, por lo que no acaba de demostrar si esos "problemas" cognitivos son propios del medio o de la falta de costumbre. Además, habría que preguntarse si no estaremos suponiendo que la lectura en papel permite un grado de concentración que no corresponde con la realidad, ya que hay estudios que demuestran su carácter voluble, poco fijo ${ }^{19}$.

De todas formas, frente al grado de dispersión de cada lector y la falta de costumbre, siempre existe la posibilidad de personalizar el acercamiento al contenido y aprovechar o limitar esas "distracciones", entrando en el terreno de los gustos y las costumbres adquiridas durante tiempo. Es decir, sería un caso más en los que se juzga un medio cuando, en realidad, son las prácticas en torno al mismo lo que sí son más censurables.

Este también parece ser el caso de Casati, ya que más que sobre el libro, su argumentación orbita sobre un género, el del ensayo, y de ahí su propensión a la narración lineal como única forma y la eliminación -por distracción- de elementos que no sean el mero texto corrido, puesto que su desasosiego procede de la introducción -probablemente abusiva y acelerada- de los soportes digitales en la enseñanza italiana, fruto de una tecnofilia políticamente llamativa, pero que no ha venido acompañada del necesario cambio en las metodologías, más acordes a los lenguajes que se están implantando, y de la formación del profesorado para los mismos.

Y es que esta preocupación sobre la enseñanza tiene como marco la sustitución de la escuela por la Red, si consideramos lo que tradicionalmente era la primera función de la institución docente: la transmisión de información. Sin duda, andamos todavía inmersos en un proceso de comprensión teórica de las tecnologías, y en el caso de la escuela italiana, ese "zapping" en el que parecen inmersos los alumnos, más avezados en las tecnologías que sus profesores en la mayoría de los casos, sí que parece establecer un cambio en la relación con la historia cultural que 
aún no logramos asimilar. De ahí esa voluntad de Casati de entender la "escuela como espacio protegido", pero habría que recordarle que también debe ponerse al día, no simplemente a través de la tecnología sino respecto a su capacidad de interpretar el mundo en el que vive.

Las posibilidades educativas en un inmediato futuro pasan por un uso y una reflexión crítica en torno a este mundo transmedia, del que uno puede desconectarse para ayudar a la concentración, pero que también aporta posibilidades como la enseñanza móvil ${ }^{20}$ o la comunicación entre estudiantes al compartir su experiencia, activando procesos colaborativos mientras potencian dinámicas de análisis y de lectura grupales, más allá incluso de la misma aula, y quizás bajo criterios de evaluación de un docente, pero en las que la enfatización de procesos colaborativos y abiertos descubren un enorme campo de ventajas.

Pero claro está, ese cuestionamiento de la escuela como fuente de información y la "sociabilidad" de los procesos educativos ponen en tela de juicio el propio concepto de "autoridad", que debe ser pensado dentro de las prácticas educativas, transformando al docente en un crisol crítico del proceso de enseñanza más que en un mero transmisor de conocimiento.

En definitiva, parece que todas las cuestiones se derivan de una problemática en torno a las costumbres, de ahí el actual éxito digital de prácticas de skeumorphism $^{21}$, que acerca el ámbito digital a una "apariencia físico-real". Aunque parece que esta estrategia va a ser propia de los inicios de las tabletas, para ayudar a la transición al mundo digital, y pronto pasaremos a otra dimensión gráfica, más minimalista y propia quizás del ámbito digital, como apunta la versión 7 de i0S y, sobre todo, la conversión gráfica que están haciendo las distintas aplicaciones a la misma.

Sin embargo, como bien nos enseñan investigaciones como el último Premio Arquímedes Patrones de intimidad, de Ana Belén López Plazas (2013), para analizar la "esfera pública" en la que nos relacionamos, debemos tener en cuenta la interacción entre mundo físico y digital. Justo ese libro nos plantea un ejercicio de estilo básico, si al diseño gráfico nos referimos: en la elección de una forma 
pertinente al contenido, un libro de este tipo reclama otro soporte que permita el uso de distintos documentos y la visualización simultánea de varios de ellos, desde planos a fragmentos de vídeo, siendo en este caso el iBook el formato idóneo para dar visibilidad a la experiencia que describe este estudio.

A diferencia de esa "liberación" del texto que supone el formato ePub, y a la espera de la estandarización que aportará el ePub3, un formato como el iBook nos permite una composición que favorece el dinamismo y la interacción, no necesariamente generadora de distracciones, sino eficaz medio para exponer correctamente toda la información, sus implicaciones y la relación entre los elementos mientras genera un relato más emotivo y mucho más atractivo.

Esto abre nuevos caminos expresivos que no implican necesariamente la eliminación del formato en papel, ni una mayor dispersión en la aprehensión del conocimiento, sino la implantación de un modelo que establece otra relación con los contenidos y que abre otras posibilidades como medio de enseñanza.

\section{Conclusiones}

Se hace más que necesaria una reflexión sobre la teoría, las creencias y las prácticas en torno a la lectura en el mundo digital. Los soportes condicionan, los medios también y simplemente debemos activar procesos de eficacia y pertinencia entre el mensaje proyectado y el lenguaje usado para ello.

Quizás la poesía necesite más espacio en blanco, más silencio; probablemente un móvil no sea lo ideal para leer mucho tiempo, pero es útil para leer noticias, responder e-mails o conectarse a Twitter o Facebook; sin duda, los libros electrónicos no decoran una estancia igual que antes sus hermanos en papel; sin embargo, las ventajas son evidentes, por la capacidad de almacenamiento, el contenido aumentado, la comodidad del formato personalizable, la calidad de las imágenes, la distribución potencialmente global, la ausencia de límites como la extensión, que en muchos casos dificultan la producción y comercialización... Incluso elementos más románticos como el don, el libro como regalo, o

DOI: ri14.v12i1.660 | ISSN: 1697-8293 | Año 2014 Volumen 12 N 1 | ICONO14 
la firma para la dedicatoria son acciones que se están resolviendo en el ámbito digital.

Así, las formas de llegar al público, la promoción y la compra también están cambiando. Igual que en la música, se venden historias sueltas, como singles sin su álbum. ¿Esto condiciona la forma de escribir? Lo importante sigue siendo la historia, pero sí es cierto que la pantalla del ordenador nos remite principalmente a "buscar información", mientras que la tableta nos devuelve a una experiencia más cercana a la del libro en papel, que está haciendo que la gente lea más ${ }^{22}$.

Lectores y escritores están cambiando, ante lo que podemos inquietarnos o apreciar nuevas formas de acercarnos a los relatos, sin plantearnos distancia alguna al mundo. Al mismo tiempo, se plantea generalmente una escritura para ser consumida rápidamente en Internet, escuchándose en numerosas redacciones del mundo que en la Red se leen artículos breves, aunque el éxito de la edición digital del New York Times, y otros diarios, parece desmentirlo. Estos "himnos al fuego lento" demuestran que en la Red todo cabe y que depende de nosotros la elección.

Pero lo que se desprende rápidamente es que, en suma, las cuestiones, los límites, no derivan de un problema formal, sino de las transformaciones profundas propiciadas por la crisis económica y por el cambio de modelo de negocio. De nosotros dependerá crear el entorno y las prácticas que nos permitan una relación crítica con los contenidos y la creación de un ámbito de enseñanza acorde a los tiempos y a las formas que cognitivamente sean más útiles para el asentamiento reflexivo de los contenidos, recordando que la literatura es un acuerdo con el mundo, pero no con el mundo tal como es, sino tal como queremos que sea.

Este artículo es fruto de la investigación desarrollada por Javier Maseda y Pedro Medina para la exposición inaugural de la Casa del Lector: $E l$ hilo de Ariadna. Lectores, navegantes (octubre de 2012), y también es consecuencia de las discusiones desarrolladas en el grupo de investigación "El valor estético y otros valores en arte: el lugar de la expresión", FFI2011-23362, financiado por el Ministerio de Ciencia e Innovación, al que Pedro Medina pertenece.

ICONO14 | Año 2014 Volumen $12 N^{\circ} 1$ | ISSN: 1697-8293 | DOI: ri14.v12i1.660 


\section{Notas}

[1] Murray, J. (1999). Hamlet en la holocubierta. El futuro de la narrativa en el ciberespacio. Barcelona: Paidós, p. 13; cit. en Villanueva, D. (2010). Lectura y nativos digitales, en Basanta Reyes, A. (coord.): La lectura. Madrid: CSIC-Arbor, 157.

[2] Ley de la lectura, del libro y de las bibliotecas, (22 de junio de 2007). Recuperado de http://www. bne.es/en/Servicios/NormasEstandares/DocumentosProfesionales/LeyDeLaLecturaDelLibroYDeLasBibliotecas/

[3] Para esta segunda dimensión, cf. Maseda, J. y Medina, P. (2012). La lectura en la época del texto digital, en El hilo de Ariadna. Madrid: Casa del Lector, 98-104.

[4] Para una aclaración al respecto, Ibíd., 88-90.

[5] Cf. Millán, J.A. (2010). Lectura digital: ¿lo mismo en otro lado?, en Basanta Reyes, A. 0p. cit., 176-181.

[6] Maseda, J. (2013). EPub3: el futuro de la edición de libros digitales. Recuperado de http:// abreelojo.com/diseno-comunicacion-y-moda/en-la-red/epub3-el-futuro-de-la-edicion-de-librosdigitales/

[7] El término "sociedad red" tal y como lo usamos hoy día fue acuñado en van Dijk, J.A.G.M. (1991). De netwerkmaat-schappij. Sociale aspecten van nieuwe media. Houten: Bohn Staflen van Loghum. Cf. Castells, M. (2006). La sociedad red: una visión global, Madrid: Alianza.

[8] Más pertinente que "participación" o "interacción". Cf. Arns, I. (2004). Interaction, Participation, Networking Art and Telecommunication, en Media Art Net 1: An Overview of Media Art. Recuperado de http://www.medienkunstnetz.de/themes/overview_of_media_art/communication/.Por interactividad se entiende la posibilidad, por parte del usuario, de interactuar con la obra, de forma simple e intuitiva, a través de interfaces especiales de consulta.

[9] Cf. Casacuberta, D. (2003). Creación colectiva. En Internet el creador es el público. Barcelona: Gedisa.

[10] Uno de los más comentados es Virilio, P. (1997). El cibermundo, la política de lo peor, ¿una política suicida? Madrid: Cátedra. Cf. Martín Prada, J. (2012). Op. cit., 161-171.

[11] Bill Nichols plantea que "la simulación del computador sugiere un 'siendo aquí (...) de lo que representa" (Nichols, B. (2000). "The Work of Culture in the Age of Cybernetic Systems", en Caldwell, J.T. (ed.). Theories of the New Media. A Historical Perspective. Londres: The Athlone Press, p. 98; cit. en Martín Prada, J. (2012). Op. cit., 306.

[12] Cf. Echeverría, J. (2005). Escritura electrónica y telebibliotecas en red, en Jarauta, F. (ed.). De Alejandría a la Biblioteca Virtual, nº 6. Santander: Fundación M. Botín, 128-130.

[13] Cf. Che cosa è cambiato veramente [cito el capítulo y no la página porque -paradójicamenteeste libro lo he leído en formato ePub, de ahí que el número de página cambie en función de tipografía y cuerpo de letra].

[14] Virilio, P. (1998). La máquina de visión. Madrid: Cátedra, 25. 
[15] Y antes de él, ya existía ese world brain de H.G. Wells, quien apuntaba que ya no poseemos la memoria, sino que somos nosotros quienes nos movemos en una memoria-Ser, en una memoriamundo (Wells, H.G. (1938). World Brain. Londres: Methuen \& Co).

[16] Cf. Guasch, A.M. (2011). Arte y archivo, 1920-2010. Genealogías, tipologías y discontinuidades. Madrid: Akal.

[17] http://www.europeana.eu/portal/, http://www.bne.es/es/Catalogos/BibliotecaDigital/ y http://www.loc.gov/wdl/

[18] Entre los numerosos artículos, uno de los más comentados ha sido Carr, N. (julio-agosto de 2008). "Is Google making us stupid?", en The Atlantic. Recuperado de http://www.theatlantic. com/doc/200807/google

[19] Zimmer, C. (15 de junio de 2009). "Stop Paying Attention: Zoning Out is a Crucial Mental State", en Discover. Cf. Millán, J.A. (2010). 0p. cit., 178-179.

[20] Comunicación Visual (9 de octubre de 2013). Recuperado de http://www.comunicacion-cultural. com/2013/10/09/transformacion-de-la-educacion-mediante-la-ensenanza-movil/

[21] Maseda, J.: Skeumorphism o el arte de imitar la realidad. Recuperado de http://abreelojo.com/ diseno-comunicacion-y-moda/en-la-red/skeuomorphism-o-el-arte-de-imitar-la-realidad/

[22] Así lo confirma, entre otros, un estudio de abril de 2012 a cargo del Pew Research Center sobre el panorama en Estados Unidos. Recuperado de http://pewresearch.org

\section{Referencias}

Basanta Reyes, A. (2010): La lectura. Madrid: CSIC-Arbor.

Benjamin, W. (1936). La obra de arte en la época de su reproductibilidad técnica, en Discursos interrumpidos I. Madrid: Taurus, 1973.

Blasco, J. (2000-). Culturas de archivo. Recuperado de http://www. culturasdearchivo.org

Calvino, I. (1988). Seis propuestas para el próximo milenio. Madrid: Siruela, 1989. Casati, R. (2013). Contro il colonialismo digitale. Istruzioni per continuare a leggere. Bari: Laterza.

Collera, V. (2012). Así leía Virginia Woolf, así leeremos nosotros, en El País. Recuperado de http://blogs.elpais.com/papeles-perdidos/2012/04/ virginiawoolfylalecturasocial.html

Derrida, J. (1969). La farmacia de Platón, en La diseminación. Barcelona: Fundamentos, 1975.

Derrida, J. (1994). Mal de archivo. Una impresión freudiana, conferencia en Londres el 5 de junio de 1994 en un coloquio internacional titulado: Memory:

ICONO14 | Año 2014 Volumen $12 N^{\circ} 1$ | ISSN: 1697-8293 | DOI: ri14.v12i1.660 
The Question of Archives. Derrida, J. (1996). Mal de archivo. Una impresión freudiana. Madrid: Trotta.

El Lissitzky (4 de julio de 1923). The Book: The Electro-Library, Topology of

Typography, en Life, Letters, Texts. Londres: Thames \& Hudson, 1992.

Fraguas, A. (17 de julio de 2012). Usted ya no lee ni escribe como antes, en $E l$

País. Recuperado de http://sociedad.elpais.com/sociedad/2012/07/16/

vidayartes/1342469862_997252.html

González, L. (2009). Nuevas formas de lectura digital. Recuperado de http://

nuevasformasdelectura.wikispaces.com/file/view/conferencia_luis_gonzalez.

pdf

López Plazas, A.B. (2013). Patrones de intimidad. Madrid: IED.

McLuhan, H.M. (1962). The Gutenberg Galaxy. The Making of Typographic Men.

Toronto: University of Toronto Press.

McLuchan, H.M. (1964). Understanding Media. The extensiones of man. Berkeley: Gingko, 2003.

Martín Prada, J. (2012). Prácticas artísticas e Internet en la época de las redes sociales. Barcelona: Akal.

Maseda, J. y Medina, P. (2012). La lectura en la época del texto digital, en El hilo de Ariadna. Madrid: Casa del Lector, 98-104.

Negroponte, N. (1995). Beign Digital. Nueva York: Vintage.

Nelson, T.H. (1992). Literary machines 90.1: Il progetto Xanadu. Padova: Muzzio, 1992.

Prensky, M. (2001): Digital Natives, Digital Inmigrants. Recuperado de http://www. marcprensky.com/writing/Prensky\%20-\%20Digital\%20Natives,\%20Digital\%20 Immigrants\%20-\%20Part1.pdf 